\title{
Thinking on Growing Urbanization, Sustainability and Food Supply: The Need of Urban Agriculture
}

\author{
Florian C. Guenther \\ Department of Philosophy, Eberhard Karls University of Tübingen, Tübingen, Baden-Württemberg, Germany \\ Email: florian.c.guenther@web.de
}

How to cite this paper: Guenther, F. C. (2019). Thinking on Growing Urbanization, Sustainability and Food Supply: The Need of Urban Agriculture. Current Urban Studies, 7, 361-370. https://doi.org/10.4236/cus.2019.73018

Received: August 12, 2019

Accepted: September 13, 2019

Published: September 16, 2019

Copyright (อ 2019 by author(s) and Scientific Research Publishing Inc. This work is licensed under the Creative Commons Attribution International License (CC BY 4.0).

http://creativecommons.org/licenses/by/4.0/

\section{(c) (7) Open Access}

\begin{abstract}
By 2050 , it is projected that 68 per cent of the world's population will live in cities. At the same time, mankind is facing the tasks to tackle climate change and to produce enough food for a growing world population. Those trends claim to rethink how cities should be planned, and how agriculture can become resilient and deliver sufficient crop yield in a changing climate. This paper offers an insight into the idea of urban agriculture as a solution for those challenges in an urban context, considering the urbanization trend, the role of cities in climate change, and the issues of limited space in urban areas and agricultural habits. It argues for an implementation of agriculture into urban planning in relation to ecological agricultural practices. Pursuing ecological practices like Conservation Agriculture improves the health of soils which results in a higher crop yield. Therefore, ecological practices in cities are a key to produce vegetables and fruits for the urban demand and to reduce transport emissions. Furthermore, with an extension of green spaces in urban areas through ecological cultivated land, the urban heat island effect can be decreased, more carbon can be stored in healthy soils, and water run-off can be improved which reduces the likelihood of urban flood events.
\end{abstract}

\section{Keywords}

Urbanization, Cities, Agriculture, Climate Change, Sustainability, Urban Agriculture

\section{Introduction: Urbanization in the Time of Climate Change}

Since more than a decade there are more people living in cities than in rural areas, and urbanization will continue to grow. While in 1950, only 30 per cent of 
the world's population lived in urban areas, this proportion has continuously grown and reached 55 per cent in 2018, and by 2050, 68 per cent of the world's population will be urban. Wars and conflicts, distress of the rural economy, the expectation of better social and economic opportunities, environmental degradation and climate stress are push factors which lead to urban migration. Besides those push factors, urbanization is also driven by the overall growth of the world population. The general trend of urbanization as well as the population growth could together add 2.5 billion people to urban areas by the middle of this century. Today, the most urbanized regions are in Northern America (with 82 per cent of its population seen as urban), Latin America and the Caribbean (81 per cent), Europe (74 per cent) and Oceania (68 per cent). Although the Asian continent has recently experienced large urban extensions due to growing cities particularly in South Asia and China, only around half of Asia's population are city dwellers. Africa's population remains mostly rural, with 43 per cent of its population residing in cities. However, both continents will become more and more urban. Almost 90 per cent of the expected urban growth of 2.5 million people will take place in Asia and Africa, which means both continents are urbanizing faster than any other region (UN, 2018).

We tend to link growing urbanization to the further expansion of cities which are already large. For instance, Shanghai, Beijing, Delhi or Dhaka already belonged to the global megacities two decades ago, but nevertheless doubled their size in the last 20 years, and are still growing. In 1995, there were 22 large cities (cities with 5 to 10 million inhabitants) and 14 megacities (10 million or more) around the globe. 20 years later, the amount of both city categories had doubled. As urbanization continues, several large cities will become megacities by 2030 (UN-Habitat, 2016). However, while large cities become megacities and megacities continue to grow, small and medium cities (less than 1 million inhabitants) are the fastest growing urban centers, especially in Africa and in Asia (UN, 2014).

Climate change has become a major cause of migration, and as the trend of rising temperatures, erratic weather patterns and more frequent and intense storms, droughts as well as floods will not stop in the next decades, an increasing amount of people will be forced to leave their homes. In 2017, 16.1 million of 30.6 million people, which were displaced inside their country, were displaced by floods and storms (IDMC, 2018). But climate as migration reason does not only refer to sudden onset events and the destruction of housing infrastructure that leave people homeless. Agriculture is a main sector in rural regions, especially in developing countries, and weather extremes and bigger variations in rainfall make life for farmers more unpredictable and are threating crop yields and food security. Thus, ensuring a livelihood becomes harder and the rural population, including many smallholder farmers, give up their old lives and head into cities to seek new opportunities and paid work.

But just as rural areas are exposed to climate change, so are cities. For in- 
stance, most urban areas are coastal, putting them at risk of flooding due to rising sea levels and heavy storms. Six of Asia's ten megacities are located on the coast (Bangkok, Jakarta, Manila, Mumbai, Shanghai and Tokyo) (Dupont \& Pearman, 2006). But cities are also affected indirectly by climate change. In the past, larger cities sourced their vegetables and fruits to a big extent locally. Today, agricultural production is primarily found in rural areas. To satisfy the urban demand of a growing urban population, the amount of food being transported to cities from rural areas has tremendously risen over the last two to three decades: by 300 per cent in India, 800 in Africa, and in Southeast Asia even by 1000 per cent. This development and the industrialization have made the route from farmer to urban consumer to a long supply chain. Climate change impacts can disrupt the supply chain by affecting production, transportation, processing or retail, resulting in urban food shortages (C40, s.a.).

About 800 million people suffer from hunger (UN, 2015), and as agricultural production is aggravated by climate change and the world population is growing, this number could increase within the next decades. Agricultural challenges, increasing urbanization and migration into cities, direct as well as indirect impacts on cities by climate change, whereat the latter is deriving from the dependency of urban areas on rural agricultural production, let arise the question of how a growing urban population can be fed in the future, in a way which is sustainable and does not exacerbate environmental degradation and climate change. The following will provide an insight into a solution that considers the role of cities in climate change, the urban potential under consideration of the issues, and the productivity of agriculture while including mitigation to climate change.

\section{Urban Challenges and Potentials}

Cities are already dealing with climate change impacts such as storms, rising sea levels or heatwaves, but they are also part of the cause. Cities create economic wealth, generate employment and drive human progress. Already today, 80 percent of the world's Gross Domestic Product (GDP) is accounted by cities (UN-Habitat, 2016). As industrial and financial centers, their contribution to the global greenhouse gas (GHG) emissions is crucial: they consume two thirds of the world's energy and are responsible for more than 70 per cent of the global $\mathrm{CO}_{2}$ emissions $(\mathrm{C} 40,2012)$. If cities expand and economic growth continues under current economic conditions, the water and energy demand will increase as well as urban emissions.

But urban areas also hold the potential to solve the problem. Firstly, cities are a melting pot of cultures and experts, thus are places of innovation and technological progress. Secondly, transforming cities into more compact areas reduces transportation routes and makes public transportation systems or other forms of locomotion (walking, cycling) more efficient. A research on the 30 largest urban areas in the US showed that walkable cities are the most educated and wealthy measured by the GDP per capita (Leinberger \& Rodriguez, 2016). Furthermore, 
by transforming grey and bald spaces into green areas by planting trees and spreading ecological diversification, positive effects on human health and well-being arise as well as improvement in air quality, reduction in the urban heat island effect, higher carbon absorption and mitigation of extreme weather events such as flood events through reduced surface water run-off.

Greening cities is essential, however, most of the medium- to mega-sized cities are dealing with space problems, above all cities in developing countries that have rapidly grown in the last decades. Urbanization has already pushed some cities in developing countries to their capacity limits. Especially cities in the Global South have grown that rapidly that local governments had neither the capacities nor the opportunities to interfere by implementing appropriate urban planning strategies. The results are large areas of informal shelters, missing infrastructure and densely populated cities without interspaces for greening options (besides further problems like pressures on health and education systems). The Nigerian city Lagos has grown over the last 60 years from a town with 300,000 inhabitants to a large city with more than 8 million. Across the decades, the growth of the city has devoured every available space, and while the population grew, the extension of infrastructure fell behind. Cities such as Mumbai, Delhi, Dhaka, Jakarta or Manila show similar developments. None of them was designed to handle a population of a size that is living there today.

Considering that the urban growth will continue, more cities could face the problem that the urban extension does not keep up with the influx of people. Already today, approximately 60 per cent of the infrastructure and settlements in cities in Asia and Africa need to be constructed yet to response to the ongoing growth (UN-Habitat, 2016; UN, 2014).

Which makes the situation even worse is that the scale of urban land occupation grows in any case. Observations on the urban development in the last decade have shown that the area covered by cities grow at a higher rate than the population increases. By 2030, the built-up area could even triple, while the urban population in developing countries will only double (UN-Habitat, 2016). Consequently, a lot of fertile land will be lost due to the construction of new settlement and street projects. Los Angeles is an extreme example of how streets claim valuable land. The city which is dominated by private transport is full of roads. 14 per cent of the incorporated land is only committed to parking (Chester, Fraser, Matute, Flower, \& Pendyala, 2015). Bituminization moreover brings the negative aspect of an increasing susceptibility of urban flood events. Normally, water dries up and is purified while it flows into groundwater. Large asphalt surfaces hinder this process; instead water flows into oceans and effect sea level rise.

\section{Status Quo of Agriculture}

Urban growth takes a lot of land while the space in cities is already limited. So how can the urban food demand be covered? The aspect of limited space in cities could lead to the idea to increase the output of conventional agricultural by 
adapting the practices to climate change, for instance by using more resistant seeds. Let us therefore look on the current state of agriculture. Agriculture has become highly industrialized in the last decades. 200 years ago, driven by efficiency and mass production, the agriculture sector developed new approaches and techniques to cultivate land in a way to produce more food by fewer farmers. With the hope of faster growing cycles, higher crop yield, ending hunger and making more profit, the industrialization of the agricultural sector has brought the use of bigger machines, synthetic fertilizers and pesticides, the acquisition and accumulation of smaller fields into larger ones, and genetically modified seeds. Today, large accumulated monoculture fields, which are run by big companies, produce food for millions of people and are dominating the agricultural picture in some regions. This agricultural development has caused a decline of smallholder farmers as for many of them their business was not profitable anymore on the emerging global agricultural market. And this development has also transformed agriculture to one of the major contributors of climate change, accounting for almost a quarter of anthropogenic GHG emissions when considering the emissions from deforestation, livestock, soil and nutrient management (Smith, Bustamante, Ahammad, Clark, Dong, Elsiddig et al., 2014).

Meanwhile, the support of that agricultural development is slowly diminishing. The industrialized cultivation of land shows on the long run more negative than positive aspects: it harms soil, pollutes and exploits groundwater, destroys surrounding ecosystems, and is highly energy demanding, mainly satisfied by fossil fuels (Hamm, 2019). Large industrialized agricultural fields, where monoculture is grown side by side, like in the Southern Spanish province Almeria, do not solely produce vegetables and fruits for domestic markets, but for whole Europe and are even shipped to Africa. This causes high transport emissions and exploits groundwater. Something similar is seen in the desert of Saudi Arabia, where crops are planted in large round fields and are primarily intended for the domestic market but are produced in a way that exhausts nearly 90 per cent of the national water consumption, almost deriving entirely from ground water.

Additionally, the industrialization of land cultivation caused a massive release of carbon. Normally, healthy soils store carbon for thousands of years. But due to land-use changes up to $357 \mathrm{Gt} C$ pre-1850 and $168 \mathrm{Gt} C$ post-1850 may have been released globally and went as $\mathrm{CO}_{2}$ into the atmosphere (Lorenz \& Lal, 2018). Besides the effect that the carbon release from soil has contributed to an increase in the atmospheric $\mathrm{CO}_{2}$ concentration, depleted and eroded soils are less fertile and less able to hold moisture which means they hold less water (Davies, 2017). The consequence is a higher likelihood of flood events in relation to more intense rainfalls.

\section{The Idea of Urban Agriculture}

Because current agricultural methods cause negative impacts on ecosystems and the climate, another approach must be found to react on the growing urban food 
demand than extending the agricultural output under current methods, an approach which does not neglect the relation of cities and climate change. Let us take another look into cities. Urban green spaces are not limited on parks, green stripes or green roofs, but may also include agricultural areas. Besides their environmental benefits, they also contribute to the urban food supply. As cities are growing, the urban population's food demand is increasing, and as traffic is seen as a major cause of emissions, bringing agricultural cultivation into cities seems to be a corollary. Cultivating crops and produce food where it is needed means a reduction of long logistic supply chains and a reduction of transport emissions. Moreover, it brings producers and consumers closer together. Since a few years there is a rising interest on the consumer's side to know where products are coming from and how they are produced. This development can be explained through several aspects such as revealed bad practices in the agriculture sector, the consideration of how an individual can contribute to a sustainable development by deciding what to consume or the conviction that eating products deriving from an organic food cultivation is healthier. And even though those concerns do not apply to everyone, bringing producer and consumer closer together could contribute to a raising awareness of the relation of food production and healthy ecosystems which has been forgotten to a vast extent in the course of industrialization and the outsourcing of agricultural practices from daily lives.

Nowadays, due to the lack of space, urban agriculture is mostly pursuing in small dimensions as urban gardening. Some households use the opportunity to use some of the available spaces in their neighborhoods (rooftops, balconies, urban community gardens) to plant vegetables or fruits and to produce hereby a part of their daily consumed foodstuffs by themselves. The development of Cuba or Havana, respectively, however shows that agriculture in urban areas have a huge potential. As the Soviet Union collapsed 30 years ago, Cuba lost its trading partner and faced an economic crisis accompanied by food scarcity. It could neither import food nor fertilizer nor fuel to transport goods on the island. The Cuban government decided to use every free space in the capital Havana as cultivation area. In the beginning of that process, crops were only grown for personal consumption, but across the years, an organic agricultural business inside the capital has evolved. Most of the consumed fresh products today are produced on fields inside the city's boundaries and are sold at local markets or in stores directly beside the fields. Because Cuba could not import any artificial fertilizers and pesticides, people were forced to cultivate in an entirely organic way. In that course of a common sustainable agricultural practice, a proficient expertise on organic agriculture has been developed through the last three decades.

\section{Using Ecological Small-Scale Farming Methods in Urban Areas}

Contrary to the widespread opinion, influenced by the big industrialized agricultural picture, promoting the agricultural sector in cities does not claim a lot of 
space, because it is less about space, but more about soil quality. The result of monocropping with only one harvest a year, the use of agrochemicals and heavy industrial machinery can be seen today: soils are increasingly becoming degraded and infertile. Indigenous methods that are pursued in accordance with natural processes or techniques such as Conservation Agriculture (minimum mechanical soil disturbance which means i.e. no tillage, permanent soil organic cover, and species diversification (FAO, Web Page)) in combination with foregoing synthetic fertilizer and pesticides, however, promote soil restoration and improve soil health. And aiming for healthier soil means revitalize microbiological life, increase the water absorption and accumulate more nutrients, which results in healthier crops. A higher water absorption rate and more nutrients in soil also lead to a higher resilience to weather extremes such as dry spells. Furthermore, healthy soil take carbon out of the atmosphere and store it safely into planted areas.

The role of soils has been widely neglected in the discussion of climate change mitigation in the past years. The political and medial focus has been, and is still, primarily set on forests when it is about land ecosystems and their potential to reduce atmospheric GHG emissions. However, the ground of forests as well as of grasslands, scrubland or cultivated land could make an important contribution to climate change mitigation, if ecological forestry and agriculture would be promoted. The potential of capture and storage of carbon in soils varies partly strongly amongst the different studies. For instance, according to the IPCC (Intergovernmental Panel on Climate Change), the global annual storage potential of carbon in soils is between 0.8 and 1.2 Gt (IPCC, 2014); the FAO (Food and Agriculture Organization of the United Nations) refers to Rattan Lal and speaks about 2.45 Gt C (FAO, 2019); and the Savory Institute and Rodale Institute estimate that if grasslands or pasture and cropland, respectively, would be shifted to regenerative organic agriculture, more Carbon could be stored than the $\mathrm{CO}_{2}$ equivalent is currently emitted globally every year (Savory Institute, 2015; Rodale Institute, 2015). Considering that $1 \mathrm{Gt} \mathrm{C}=3.664 \mathrm{Gt} \mathrm{CO}_{2}$, and in 2017 around $36 \mathrm{Gt} \mathrm{CO}_{2}$ were emitted (Global Carbon Project, Web Page), already the lower numbers of the IPCC and FAO (converted into $\mathrm{CO}_{2}: 2.93 \mathrm{Gt} \mathrm{CO} /$ year $8.98 \mathrm{Gt} \mathrm{CO}_{2} /$ year) show what an important role soil carbon sequestration could have.

The combination of healthy soils, a permanent soil coverage and planting diverse crop species throughout the year allows to do multiple harvests per year that consequently leads to a higher crop yield. Ecological agricultural methods could even increase the yield in tropical regions by 120 to 180 per cent in comparison to conventional agricultural techniques (Koerber, Kretschmer, Prinz, \& Dasch, 2009).

As available areas in urban areas are scarce, healthy soils and a permanent cultivation are key to achieve a crop yield through which the urban food demand can be covered, or at least to a higher degree as it is today. Moreover, farming on 
a smaller scale allows to plant more precisely and to use the available area more efficiently. Already in 1980, the FAO Census of Agriculture carried out that farms between 0.5 and 6 hectares can be as 4 times more productive as farms of 15 and more hectares (Whitefield, 2004). Therefore, ecological small-scale farming practices are ideal for urban areas. Such practices do not even need a full-time care but can be done on a half-time basis or as a kind of hobby, whether for the own consumer's need, like in the beginnings of the Cuban agricultural transformation, or for sale. Hereby, the cultivation of urban areas would push local food markets in cities without stressing ecosystems and the climate. The cultivation of urban areas has furthermore a socioeconomic benefit. Food shortages and supply disruptions drive up costs whereby especially the urban poor suffer. Extremely poor households in developing countries spend between 48 to 85 per cent of their budget on food (C40, s.a.). Growing more resilient vegetables and fruits, for personal use or for local markets without relying on long supply chains that push up costs which must be finally paid by end consumers, would give the urban poor more financial opportunities.

\section{Conclusion}

It is necessary to re-understand the cultivation of crops and plants as agro-culture, no longer as agro-industry. We are experiencing the limits of the industrialized agriculture right now despite its high resource demand. The industrial food chain uses around 75 per cent of the world's agricultural resources, but it only produces food for less than 30 per cent of the world's population. This means 70 percent of the global food production is provided by smallholder farmers in rural as well as in urban areas (ETC Group, 2017).

While urbanization will not be stopped and climate change is a major threat for food security, approaches must be applied that guarantee a sustainable and sufficient food production. Africa will experience the highest increase in urbanization in the coming decades. In many African countries, agriculture still relies on subsistence agriculture-33 million family farms cultivate less than 2 hectares, accounting for 80 per cent of farms (NEPAD, 2013). In some African countries, the subsistence economy even carries an essential contribution to the GDP. In times of more frequent weather extremes and erratic weather patterns that aggravate farming, the escape of small farm households into urban centers to seek new opportunities could therefore not only bring serious impacts on food supply but could also end in setbacks for national economies.

Considering urbanization and the need for a sustainable, resilient food production, urban planning must involve the creation of agricultural areas. In developed countries, settlements and infrastructure are already built and will predominantly shape urban living for the next decades. Thus, creating green and agricultural areas is challenging. However, greening rooftops, urban gardening and the conservation and extension of green spaces can support a sustainable development. In developing countries, we find a different situation. That around 
60 per cent of the infrastructure and settlements in African and Asian cities need to be constructed yet, could turn out as a real chance to transform cities into sustainable living areas. And even though the cultivation area in cities may remain limited, by planting more precisely and using ecological planting methods, crop yields can be increased due to healthier soils. Thereby long supply chains become redundant by implementing the idea of green cities and urban agriculture, especially keeping in mind that the fastest growing urban areas are small and medium cities where free spaces are more likely to find, and green infrastructure opportunities are less determined by dense built-up areas as it is usually the case in large cities.

\section{Conflicts of Interest}

The author declares no conflicts of interest regarding the publication of this paper.

\section{References}

C40 Cities (2012). Why Cities? Ending Climate Change Begins in the City. https://www.c40.org/ending-climate-change-begins-in-the-city

C40 Cities (s.a.). Cities Are Hungry for Climate Action. https://www.c40.org/other/the-future-we-don-t-want-cities-are-hungry-for-climate-act ion

Chester, M., Fraser, A., Matute, J., Flower, C., \& Pendyala, R. (2015). Parking Infrastructure: A Constraint on or Opportunity for Urban Redevelopment? A Study of Los Angeles County Parking Supply and Growth. Journal of the American Planning Association, 81, 268-286. https://doi.org/10.1080/01944363.2015.1092879

Davies, J. (2017). The Business Case for Soil. Nature, 543, 309-311. https://doi.org/10.1038/543309a

Dupont, A., \& Pearman, G. (2006). Heating up the Planet: Climate Change and Security. Lowy Institute Paper 12. Sydney: Lowry Institute for International Policy.

ETC Group (2017). Who Will Feed Us? The Peasant Food Web vs. the Industrial Food Chain. Val David, Davao City, Mexico City.

FAO (Food and Agriculture Organization of the United Nations) (2019). Recarbonization of Global Soils: A Dynamic Response to Offset Global Emissions. Rome: FAO and Global Soil Partnership.

FAO (Food and Agriculture Organization of the United Nations). Conservation Agriculture (Web Page). http://www.fao.org/conservation-agriculture/en/

Global Carbon Project Global Carbon Atlas (Web Page). http://www.globalcarbonatlas.org/en/CO2-emissions

Hamm, M. (2019). 8 Ways We Need to Change the Way We Eat. https://www.weforum.org/agenda/2019/07/how-to-stop-a-global-food-crisis/

IDMC (Internal Displacement Monitoring Centre) (2018). Global Report on Internal Displacement. Geneva.

IPCC (Intergovermental Panel on Climate Change) (2014). Climate Change 2014: Mitigation of Climate Change. Contribution of Working Group III to the Fifth Assessment Report of the Intergovernmental Panel on Climate Change. Cambridge, New York: 
Cambridge University Press. https://doi.org/10.1017/CBO9781107415416

Leinberger, C. B., \& Rodriguez, M. (2016). Foot Traffic Ahead: Ranking Walkable Urbanism in America's Largest Metros. Washington DC: The George Washington University School of Business.

Lorenz, K., \& Lal, R. (2018). Agricultural Land Use and the Global Carbon Cycle. In K. Lorenz, \& R. Lal (Eds.), Carbon Sequestration in Agricultural Ecosystems (pp. 1-37). Cham: Springer International Publishing. https://doi.org/10.1007/978-3-319-92318-5_1

NEPAD (New Partnership for Africa's Development) (2013). Agriculture in Africa: Transformation and Outlook. Midrand.

Rodale Institute (2015). Regenerative Organic Agriculture and Climate Change: $A$ Down-to-Earth Solution to Global Warming. Kutztown, PA: Rodale Institute.

Savory Institute (2015). Restoring the Climate through Capture and Storage of Soil Carbon through Holistic Planned Grazing. Boulder, CO: Savory Institute.

Smith, P., Bustamante, M., Ahammad, H., Clark, H., Dong, H., Elsiddig, E. A. et al. (2014). Agriculture, Forestry and Other Land Use (AFOLU). In IPCC (Ed.), Climate Change 2014: Mitigation of Climate Change. Contribution of Working Group III to the Fifth Assessment Report of the Intergovernmental Panel on Climate Change (pp. 811-922). Cambridge, New York: Cambridge University Press.

UN (United Nations) (2014). World Urbanization Prospects: The 2014 Revision, Highlights (ST/ESA/SER.A/352). New York: United Nations, Department of Economic and Social Affairs, Population Division. https://doi.org/10.18356/527e5125-en

UN (United Nations) (2015). The Millennium Development Goals Report 2015. New York: United Nations.

UN (United Nations) (2018). World Urbanization Prospects: The 2018 Revision-Key Facts. New York: United Nations Department of Economic and Social Affairs.

UN-Habitat (2016). Urbanization and Development: Emerging Futures: World Cities Report 2016. Nairobi: UN-Habitat.

von Koerber, K., Kretschmer, J., Prinz, S., \& Dasch, E. (2009). Globale Nahrungssicherung für eine wachsende Weltbevölkerung-Flächenbedarf und Klimarelevanz sich wandelnder Ernährungsgewohnheiten. Journal für Verbraucherschutz und Lebensmittelsicherheit, 4, 174-189. https://doi.org/10.1007/s00003-009-0486-1

Whitefield, P. (2004). Earth Care Manual: A Permaculture Handbook for Britain \& Other Temperate Climates. Portsmouth: Permanent Publications. 